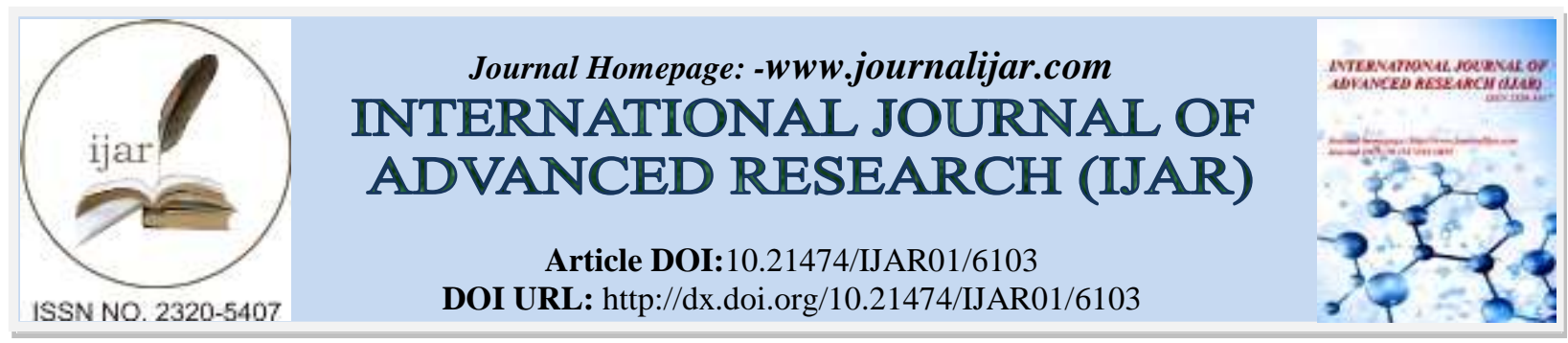

RESEARCH ARTICLE

\title{
MICROBIOLOGICAL PROFILE OF URINARY TRACT INFECTION IN CHILDREN WITH VESICOURETERIC REFLUX AND COMPARISON OF E COLI AND NON-E COLI INFECTIONS.
}

\author{
Dr. Shaista Nazir, Prof. Syed Khursheed Ahmad, Dr. Tariq Nazir Lone , Dr. Gowhar Nazir Mufti , Dr. Asifa \\ Bhat, Dr. Shazia Benazir, Dr. Dekyong Angmo and Dr. Lenah Bashir.
}

\section{Manuscript Info}

Manuscript History

Received: 19 October 2017

Final Accepted: 20 November 2017

Published: December 2017

Key words:-

Urinary tract infection, Vesicoureteric reflux.

\begin{abstract}
Background: The urinary tract is a common site of infection in the paediatric population. Vesicouretric reflux (VUR) refers to the retrograde passage of urine from the bladder into the ureter. A high incidence of VUR is reported in patients undergoing evaluation for UTI. The aetiology of paediatric UTI and the antibiotic susceptibility of urinary pathogens in both the community and hospitals have been changing, and drug resistance has become a major problem. With this background, the present study was conducted to observe the profile of the paediatric UTI, to find out the bacterial pathogens involved and their antimicrobial susceptibility pattern in patients with VUR and consecutive renal scarring in these patients at a tertiary care centre in North India. Material and Method: All patients from 0-15 years of age diagnosed with urinary tract infection and vesicoureteral reflux attending the OPD and admitted in the hospital were included in the study. Urine was inoculated on Hicrome agar using a calibrated loop the plates were examined after 24 hours for colony morphology, significant colony count, and their characteristics. Patients underwent VCUG and DMSA scan when indicated. Results: Overall males were more affected than females. E Coli was the commonest organism grown on culture. Quinolones, cotrimoxazole and amoxicillin were among the less effective drugs where as nitrofurantoin, aminoglycosides were highly effective drugs. Renal scars were more commonly seen in higher grade of reflux whereas there was no difference in scarring in E Coli vs Non E Coli infections. Conclusion: Cotrimoxazole should not be used for antimicrobial prophylaxis where as nitrofurantoin is a better option for prophylaxis. Aminoglycosides can be used as empirical therapy till the results of antimicrobial sensitivity are available. Renal scars are seen more often in higher grades of vesicoureteric reflux and thus need to be treated aggressively.
\end{abstract}

Copy Right, IJAR, 2017,. All rights reserved.

\section{Introduction:-}

The urinary tract is a common site of infection in the paediatric population. Although urinary tract infection is relatively benign in adults, in the paediatric population it is well recognized cause of acute morbidity and chronic medical illness, like hypertension and renal insufficiency later in adulthood ${ }^{1}$. Incidence of UTI varies with age of the child. Five per cent of children below two years with fever have UTI. In the first year of life, UTI is seen more 
commonly in boys (3.7\%) than in girls (2\%). Thereafter, the UTI has been reported to be among 3 per cent girls and 1.1 per cent boys ${ }^{2}$. Vesicouretric reflux (VUR) refers to the retrograde passage of urine from the bladder into the ureter. A much higher incidence of VUR (between 30\% to 40\%) is reported in patients undergoing evaluation for UTI. Boys with VUR tend to present at a relatively young age (25\% if younger than 3 months), and younger children tend to have the most severe degrees of reflux ${ }^{3}$.

Antimicrobials are important in UTI in the management of acute pyelonephritis and antimicrobial prophylaxis in children with VUR especially in children younger than 2 years. It is important to know the common pathogens and their antimicrobial resistance patterns in a given population so that the clinician can start the treatment before the antimicrobial sensitivity patterns are known. Susceptibility patterns of the bacterial isolates vary with geographic region and act as a reference for guiding the empirical therapy. The aetiology of paediatric UTI and the antibiotic susceptibility of urinary pathogens in both the community and hospitals have been changing, and drug resistance has become a major problem ${ }^{4}$. With this background, the present study was conducted to observe the profile of the paediatric UTI, to find out the bacterial pathogens involved and their antimicrobial susceptibility pattern in patients with VUR and consecutive renal scarring in these patients at a tertiary care centre in North India.

\section{Materials and Methods:-}

This was a prospective study carried out at the Departments of Microbiology and Paediatric Surgery at our Institute from Aug 2014 to Feb 2016. All patients from 0-15 years of age diagnosed with urinary tract infection and vesicoureteral reflux attending the OPD and admitted in the hospital were included in the study. Urine sample was collected by collecting midstream urine, catheterization or suprapubic aspiration. It was screened for infection by microscopic examination for presence of pus cells. Presence of pus cells more than 10/HPF was taken as significant. Urine was inoculated on Hicrome agar using a calibrated loop. The plates were streaked to obtain isolated colonies. After this, the cultures were incubated at $35^{\circ} \mathrm{C}$ for 24 hours. Next day, the plates were examined for colony morphology, significant colony count, and their characteristics.Antimicrobial susceptibility of the isolates was performed by Kirby-Bauer disc diffusion method. The zones of growth inhibition around each of the antibiotic discs were measured to the nearest millimetre. The diameter of the zone is related to the susceptibility of the isolate and to the diffusion rate of the drug through the agar medium. The zone diameters of each drug were interpreted using the criteria published by the Clinical and Laboratory Standards Institute (CLSI). ${ }^{5}$ Patients were administered antibiotics as per culture sensitivity for 5-7 days, and a repeat culture was obtained to check for resolution of infection.

All patients were subjected to ultrasonography to look for kidney size, hydronephrosis, ureteric dilatation, etc. Patients with febrile UTI and recurrent urinary tract infection were subject to VCUG after resolution of infection as per American Academy of Paediatrics (AAP) guidelines, in order to look for presence of VUR, which was graded according to the international classification of vesicoureteral reflux ${ }^{6}$.. All patients with VUR were also subject to a DMSA scan to look for the presence of renal scars. The patients were followed in the Department of Pediatric Surgery monthly for a minimum of 6 months. Data regarding patients' characteristics, the most common isolates, their sensitivity, grades of reflux, and presence of renal scars were analysed statistically and conclusions drawn.

Results:-

\begin{tabular}{|l|l|l|l|l|l|l|l|}
\hline \multirow{2}{*}{ Age } & $\begin{array}{l}\text { No of patients with UTI without } \\
\text { VUR(n=250) }\end{array}$ & $\begin{array}{l}\text { No of patients with UTI with } \\
\text { VUR(n=70) }\end{array}$ & $\begin{array}{l}\text { Total } \\
(\mathbf{n}=320)\end{array}$ \\
\cline { 2 - 8 } & Males & Females & Total & Males & Females & Total & \\
\hline $\mathbf{0 - 1}$ & 35 & 18 & 53 & 25 & 7 & 32 & 85 \\
\hline $\mathbf{1 - 5}$ & 65 & 56 & 121 & 18 & 9 & 27 & 148 \\
\hline$>\mathbf{5}$ & 19 & 57 & 76 & 2 & 9 & 11 & 87 \\
\hline Total & 119 & 131 & 250 & 45 & 25 & 70 & 320 \\
\hline
\end{tabular}

Table 1:-Age and sex distribution of urinary tract infections in children.

\begin{tabular}{|l|l|l|}
\hline Organism & No of patients & Percentage \\
\hline E. Coli & 47 & 67.1 \\
\hline K. Pneumonia & 10 & 14.3 \\
\hline Enterococcus & 9 & 12.9 \\
\hline Acinetobacter & 3 & 4.3 \\
\hline Proteus & 1 & 1.4 \\
\hline
\end{tabular}


Total 70

100

Table 2:- Organisms grown on culture in children with UTI and vesicoureteric reflux.

\begin{tabular}{|l|l|l|l|l|l|l|l|}
\hline Organism & Amikacin & NFT & Imipenem & Cotrimoxazole & Ciprofloxacin & Ceftriaxone & Ceftazidime \\
\hline E. Coli & $43(91.5 \%)$ & $40(85 \%)$ & $32(68 \%)$ & $10(21.2 \%)$ & $15(31.9 \%)$ & $15(31.9 \%)$ & $11(23.4 \%)$ \\
\hline $\begin{array}{l}\text { K. } \\
\text { Pneumonia }\end{array}$ & $4(40 \%)$ & $3(30 \%)$ & $4(40 \%)$ & $2(20 \%)$ & $3(30 \%)$ & $2(20 \%)$ & $5(50 \%)$ \\
\hline Enterococcus & $0(0 \%)$ & $8(88.8)$ & $0(0 \%)$ & $0(0 \%)$ & $5(55.5 \%)$ & $0(0 \%)$ & $0(0 \%)$ \\
\hline Acinetobacter & $2(66.7 \%)$ & $0(0 \%)$ & $2(66.7 \%)$ & $2(66.7 \%)$ & $2(66.7 \%)$ & $0(0 \%)$ & $0(0 \%)$ \\
\hline Proteus & $1(100 \%)$ & $0(0 \%)$ & $0(0 \%)$ & $0(0 \%)$ & $1(100 \%)$ & $1(100 \%)$ & $0(0 \%)$ \\
\hline Total & $50(71 \%)$ & $49(70 \%)$ & & & $26(37.1 \%)$ & $18(25.7 \%)$ & $16(22.8 \%)$ \\
\hline
\end{tabular}

Table 3:- Sensitivity of different organisms in children with UTI and vesicoureteric reflux

\begin{tabular}{|l|l|l|}
\hline Grade of reflux & No of patients & Percentage \\
\hline $\mathbf{0}$ & 39 & 27.8 \\
\hline $\mathbf{1}$ & 10 & 7.1 \\
\hline $\mathbf{2}$ & 33 & 23.5 \\
\hline $\mathbf{3}$ & 30 & 21.4 \\
\hline $\mathbf{4}$ & 16 & 11.4 \\
\hline $\mathbf{5}$ & 12 & 8.5 \\
\hline Total & 140 & 100 \\
\hline
\end{tabular}

Table 4:- VCUG findings in patients of UTI with vesicoureteric reflux.

\begin{tabular}{|l|l|l|l|l|l|}
\hline Grade of reflux & & $\begin{array}{l}\text { No of renal } \\
\text { units }\end{array}$ & $\begin{array}{l}\text { No of renal } \\
\text { units with scars }\end{array}$ & Percentage & \multirow{2}{*}{-value } \\
\hline \multirow{2}{*}{ Low grade } & I & 10 & 0 & 0 & \multirow{2}{*}{0.006} \\
\cline { 2 - 5 } & II & 33 & 6 & 18.1 & \\
\cline { 2 - 5 } & III & 30 & 10 & 33.3 & \\
\cline { 1 - 5 } High Grade & IV & 16 & 8 & 50 & \\
\cline { 2 - 5 } & V & 12 & 9 & 66.7 & \\
\hline
\end{tabular}

Table 5:-Renal scars vs grade of reflux in children with UTI and vesicourteric reflux.

\begin{tabular}{|c|c|c|c|c|}
\hline Renal scarring & No scars & Scars & $\begin{array}{l}\text { Percentage with } \\
\text { scars }\end{array}$ & P-value \\
\hline 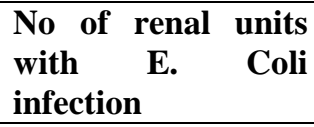 & 78 & 20 & 20 & \multirow[t]{3}{*}{0.27} \\
\hline $\begin{array}{l}\text { No of renal units } \\
\text { with non E Coli } \\
\text { infection }\end{array}$ & 29 & 13 & 30.9 & \\
\hline Total & 107 & 33 & 23.5 & \\
\hline
\end{tabular}

Table 6:-Renal scarring in E Coli Vs Non E. Coli infection

\section{Discussion:-}

Urinary tract infection (UTI) is a common problem at the pediatric age. Various studies show that by the age of 7 years, $8 \%$ of girls and $2 \%$ of boys have suffered an episode of UTI. Although predominant in females in overall pediatric age, it is more common in boys of preschool age. ${ }^{7}$ Although UTI is known to affect more females than males overall, our study found overall male predominance. Similar observations have been made by NeelamTaneja et al.and Eltigani MA et al. ${ }^{8}$ This male predominance could partially be explained by parents paying more attention to the male child in seeking medical treatment.Most studies on vesicoureteric reflux (VUR) suggest that general occurrence in healthy children is around $1-2 \%$. However, different studies have shown a wide range of prevalence from $0-30 \%{ }^{9}$. This variation may be attributed to different yardsticks and sensitivity in different imaging methods. The issue is further confounded by the inclusion of non-uniform age groups in the study. 
It is difficult to diagnose UTI in the pediatric population - especially among children less than 5 years of age - as they present with non-specific non-localizing signs and symptoms such as vomiting, fever, irritability, etc. Therefore, the clinician needs to have high degree of suspicion for diagnosing UTI at this age. As reported in other studies, most UTIs are caused by uropathogenic Escherichia coli, followed by Klebsiella pneumonia, Enterococcus, Proteus, Acinetobacter, etc. ${ }^{10,11}$ In our study, the most common organisms isolated were E. coli (67\%), K. pneumonia (14.3\%), Enterococcus (12.9\%), Acinetobacter (4.3\%), and Proteus (1.4\%). These findings are consistent with findings by other studies by Mcloughlin TG. et al. ${ }^{12}$ (2003), Sakran W et al. ${ }^{13}$ (2003), Palak Gupta et al. ${ }^{14}$ (2015) . In this study, overall isolates were highly sensitive to amikacin (71\%) and nitrofurantoin (70\%). E. coli, which was the most common isolate, also showed similar sensitivity pattern: amikacin (91.5\%) and nitrofurantoin $(85 \%)$. E. coli was less sensitive to cotrimoxazole (21.2\%), ceftriaxone (31.9\%), and ciprofloxacin (31.9\%).Similar observations were made by Shrestha et al. ${ }^{15}$ and Sharma A et al ${ }^{16}$.

Klebsiella showed $40 \%$ sensitivity to amikacin and $30 \%$ to nitrofurantoin in our study. Sharma et al. ${ }^{16}$ (2011) found $100 \%$ sensitivity to amikacin and $83.3 \%$ to nitrofurantoin. Kumariet al. ${ }^{17}$ (2005) found that $96.0 \%$ of Klebsiella were sensitive to amikacin. This variation in sensitivity pattern in Klebsiella may either be due to increasing resistance of organisms or due to limited number of isolates. Nitrofurantoin and cotrimoxazole are frequently used in urinary tract infections as chemoprophylaxis among children with vesicoureteric reflux. Our data suggests that nitrofurantoin has better activity, and bacteria have lower resistance to this drug, and should therefore be used for prophylaxis in children, especially among patients with VUR. Cotrimoxazole used to be given as an empirical therapy for UTI, as it was highly effective. However, in our study, cotrimoxazole was the least effective antibiotic against overall isolates.Hence we do not recommend it to be used as an empirical agent for prophylaxis for UTI in children. Our study showed low sensitivity of the organisms to quinolones. We found ciprofloxacin to be only $37 \%$ effective overall and $31.9 \%$ sensitive for E. coli. Although quinolones are not used in children, the finding is worrisome, and probably due to the overuse of quinolones in the community. Other studies show a similar pattern of resistance in isolates of E. coli against quinolones. Bijendra Raj et al. ${ }^{18}$ (2014) found sensitivity of $10 \%$ against ciprofloxacin. This shows that quinolones should not be used empirically to treat UTI.

Voiding cystourethrography (VCUG) is the screening urologic imaging study of choice for detecting VUR. Vesicoureteral reflux can be a risk factor for renal scarring in the presence of UTI through the transport of microbes from the urinary bladder to the kidneys. The acquisition of renal scarring through the association of reflux, urinary infection, and intrarenal reflux has been observed clinically and experimentally. ${ }^{1920}$ Nuclear scintigraphy can detect areas of acute renal inflammation and chronic scarring, and this capability has changed imaging of pediatric UTIs. In our study, DMSA findings showed that $23.5 \%$ of the children (33 Of 140) had renal scarring. Scarring was associated with low-grade VUR in 21\% (16 out of 73) cases and with high-grade VUR in 60\% (17 out of 28) cases. Scarring was significantly associated with high-grade VUR $(\mathrm{p}=0.006)$. These findings are consistent with other studies. Falakaflaki B et al. ${ }^{21}$ (2014) observed scars in 33.3\% (12 out of 36) cases in low-grade reflux and 76.9\% (10 out of 13) cases in high-grade refluxon a sample of 49 UTI patients with VUR . Ljiljana Jaukovic et al. ${ }^{22}(2009)$, in 118 UTI patients with VUR, observed renal scars in 26\% (22 of 84) in low-grade reflux and 56\% (19 of 34) of cases in high-grade reflux. These studies and our data clearly show that scarring is more common in higher grade of reflux.

Between $65 \%$ and $90 \%$ of urinary tract infections (UTIs) in children are caused by Escherichia coli. Other pathogens include Klebsiella species, Proteus species, Pseudomonas aeruginosa, and Enterococcus species. Very few studies have compared the clinical and bacteriological characteristics in E. coli and non-E. coli infections.

S Friedman et al. ${ }^{23}$ (2006) compared the clinical and laboratory characteristics of infants and children with urinary tract infection caused by E. coli $(n=107)$ and other pathogens $(n=32)$. They found a significantly higher association of non-E. coli disease with urinary tract anomalies, younger age, and previous antibiotic treatment. Underlying urinary tract anomalies were noted in 18 patients, of whom 14 (77\%) were infected by non-E. coli pathogens. The most frequent anomaly was grade III-IV vesicoureteral reflux (50\%), followed by hydronephrosis (22.7\%). We studied the clinical features in E. coli and non-E. coli urinary tract infections in our patients. Our results showed non-E. coli infections to be more common in males, even though the difference was not significant. Renal scarring was more common in patients with non-E. coli infections compared to patients with E. coli infections; the difference was insignificant $(\mathrm{p}=0.27)$. Our data was consistent with the study by Falakaflaki $\mathrm{B}^{21}(2014)$, who compared renal scarring in E. coli and non-E. coli infections, and found no significant difference in renal scaring between the two groups. 


\section{Bibliography:-}

1. Shortlife M D L, Shinghal R., and SetoE.H.,'Pediatric Urinary Tract Infection' In Pediatric Urology, Gearhart J.P., Rink R.C.andMouriquand P.D.E., WB Saunders, Philadelphia. 2001; 16:237-258.

2. Steven L Chang, Linda D. Shortliffe . Pediatric Urinary Tract Infections. PediatrClin N Am 53 (2006) 379400.

3. Eugene Minevich, Curtis A. Sheldon, 'Urinary tract infection and vesicoureteral reflux' in Ashcraft's pediatric surgery / [edited by] George Whitfield Holcomb III, J. Patrick Murphy ; associate editor, Daniel J. Ostlie. — 5 th ed.

4. Gupta P, Mandal J, Krishnamurthy S, Barathi D, Pandit N. Profile of urinary tract infections in paediatric patients. Indian J Med Res. 2015 Apr;141(4):473-7.

5. Clinical and Lab Standards Institute (CLSI). Performance standards for antimicrobial susceptibility testing. $16^{\text {th }}$ informational suppliments CLSI document. M2 Wayne Pa: 2006.

6. Roberts KB.Revised AAP Guideline on UTI in Febrile Infants and Young Children.Am Fam Physician. 2012 Nov 15;86(10):940-6

7. Saha B. K; Haque M. M; Paul S. K; Alam M. S; Karim M. S. Study of Association of Primary Vesicoureteric Reflux in Children Suffering from Urinary Tract Infection. ChattagramMaa-O-Shishu Hospital Medical College Journal Volume 13, Issue 1, January 2014

8. Ali El-Tigani M. A., AlfakiEnaam M, Abdelraheem Mohamed B Primary vesicoureteral reflux in Sudanese children Saudi J Kidney Dis Transpl 2014;25(4):900-905

9. Marzouk M, Ferjani A, Haj Ali M, Boukadida J. [Profile and susceptibility to antibiotics in urinary tract infections in children and newborns from 2012 to 2013: Data from 1879 urine cultures]. Arch Pediatr. 2015 May;22(5):505-9

10. VenkatRamanan P, Sharma S, Krishna V.Changing profile of pediatric community-acquired UTI in a hospital in South India.J Trop Pediatr. 2014 Dec;60(6):483.

11. Singh SD, Madhup SK.Clinical profile and antibiotics sensitivity in childhood urinary tract infection at Dhulikhel Hospital.Kathmandu Univ Med J (KUMJ). 2013 Oct-Dec;11(44):319-24.

12. Mcloughlin,TG Jr., Joseph, MM. Antibiotic resistance patterns of uropathogens in pediatric resistance emergency department patients. AcadEmerg Med.2003 Apr;10(4): 347-51.

13. Sakran,W.,Miron,D. Halevy, R., Colodner, R. Smolkin, V., Koren, A. Community acquired Urinary Tract Infection among hospitalized children in Israel: pathogens, susceptibility patterns and urinary tract anomalies. Harefuah.2003 Apri;142(4):249-52,320,319

14. Gupta P, Mandal J, Krishnamurthy S, Barathi D, Pandit N. Profile of urinary tract infections in paediatric patients. Indian J Med Res. 2015 Apr;141(4):473-7.

15. Komp Lindgren P, Klockars O, Malmberg C, Cars O.Pharmacodynamic studies of nitrofurantoin against common uropathogens.J AntimicrobChemother. 2015 Apr;70(4):1076-82.

16. Sharma A1, Shrestha S, Upadhyay S, Rijal P. Clinical and bacteriological profile of urinary tract infection in children at Nepal Medical College Teaching Hospital. Nepal Med Coll J. 2011 Mar;13(1):24-6.

17. Kumari N, Ghimire G, Magar JK, Mohapatra TM, Rai A.Antibiogram pattern of isolates from UTI cases in Eastern part of Nepal. Nepal Med Coll J. 2005 Dec;7(2):116-8.

18. Raghubanshi B.R., Shrestha, D., Chaudhary, M., Karki, B.M.S., Dhakal, A.K. 2014. Bacteriology of urinary tract infection in paediatric patients. At KIST Medical College Teaching Hospital. J. Kathmandu Med. College, 3(1): 7.

19. Zhang $\mathrm{X}, \mathrm{Xu} \mathrm{H}$, Zhou L, Cao Q, Shen Q, Sun L et al.Accuracy of early DMSA scan for VUR in young children with febrileUTI.Pediatrics. 2014 Jan;133(1):e30-8

20. Wongbencharat K, Tongpenyai Y, Na-Rungsri K.Renal ultrasound and DMSA screening for high-grade vesicoureteral reflux.Pediatr Int. 2016 Mar;58(3):214-217.

21. Falakaflaki B, Mazloomzadeh S, Molaei Z. The Incidence of Renal Scarring and its Related Factors in Children with First Pyelonephritis. Journal of Pediatric Nephrology. 2014;2(1):30-4.

22. Jaukovic L, Ajdinovic B, Dopudja M, Krstic Z. Renal scintigraphy in children with vesicoureteral refluxIndian J Pediatr. 2009 Oct;76(10):1023-6.

23. S Friedman, S Reif, A Assia, I Levy.Clinical and laboratory characteristics of non-E coli urinary tract infections. Arch Dis Child 2006;91:845-846. 